
\title{
$\begin{array}{ll}\text { Research Square } & \begin{array}{l}\text { Preprints are preliminary reports that have not undergone peer review. } \\ \text { They should not be considered conclusive, used to inform clinical practice, } \\ \text { or referenced by the media as validated information. }\end{array}\end{array}$
}

\section{Characterization and Genomic Analysis of an Efficient Dibutyl Phthalate- Degrading Bacterium Microbacterium sp. USTB-Y}

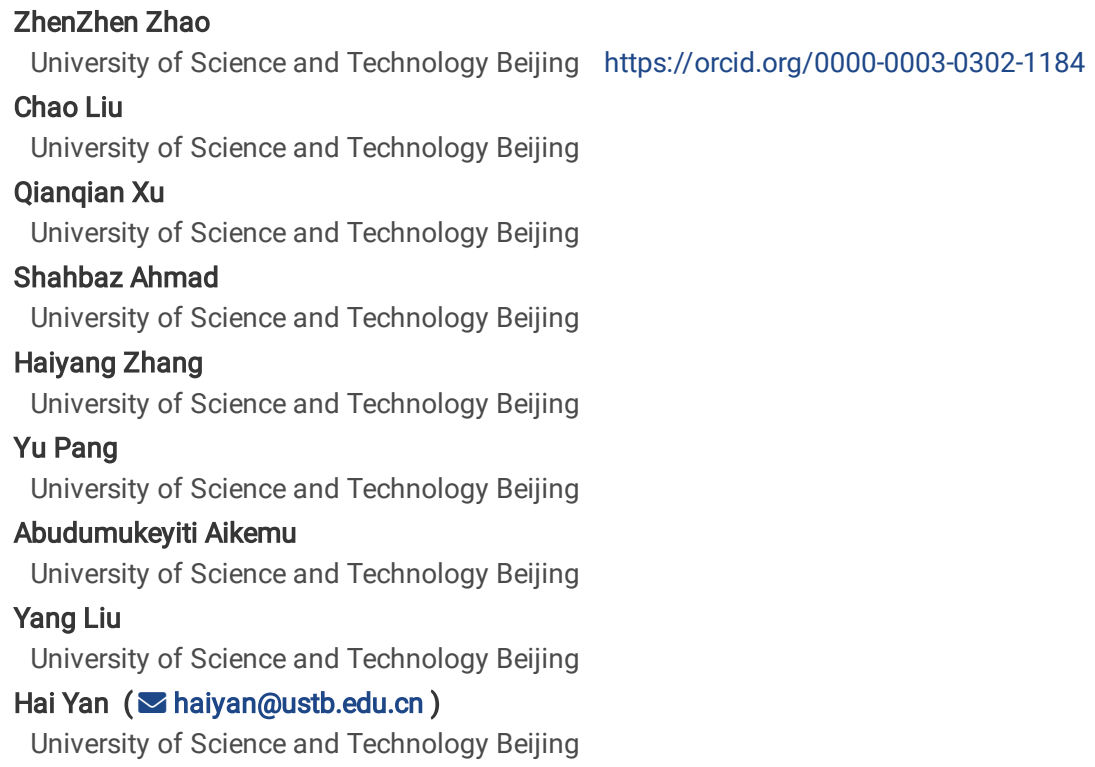

Version of Record: A version of this preprint was published at World Journal of Microbiology and Biotechnology on November 5th, 2021. See the published version at https://doi.org/10.1007/s11274-021-03181-5. 


\begin{abstract}
A promising bacterial strain for biodegrading dibutyl phthalate (DBP) was successfully isolated from activated sludge and characterized as a potential novel Microbacterium sp. USTB-Y based on 16S rDNA sequence analysis and whole genome average nucleotide identity (ANI). Initial DBP of $50 \mathrm{mg} / \mathrm{L}$ could be completely removed by USTB-Y both in mineral salt medium and in DBP artificially contaminated soil within $12 \mathrm{~h}$ at the optimal culture conditions of pH 7.5 and $30^{\circ} \mathrm{C}$, which indicates that USTB-Y has a strong ability in DBP biodegradation. Phthalic acid (PA) was identified as the end-product of DBP biodegraded by USTB-Y using GC/MS. The draft genome of USTB-Y was sequenced by Illumina NovaSeq, and 29 and 188 genes encoding for putative esterase/carboxylesterase and hydrolase/alpha/beta hydrolase were annotated based on NR (non redundant protein sequence database) analysis, respectively. Gene3781 and gene3780 from strain USTB-Y showed 100\% identity with $d p e H$ and $m p e H$ from Microbacterium sp. PAE-1. But no phthalate catabolic gene $(p h t)$ cluster was found in the genome of strain USTB-Y. This information will be valuable for obtaining a more holistic understanding on diverse genetic mechanisms of PAEs-biodegrading Microbacterium sp. strains.
\end{abstract}

\title{
Introduction
}

Phthalate esters (PAEs), composed of a benzene ring and two side chains at the ortho-position, are the most widely used plasticizers in plastic products, medical supplies, home appliances and toys (Daiem et al. 2012). In 2014, the global consumption of plasticizers reached 8.4 million tons, in which PAEs account for $70 \%$ (Ren et al. 2018). Due to physical bond (such as molecular forces and polymerization forces) to plastic products, PAEs are easily released into environment (Benjamin et al. 2015), such as agricultural soil (Lü et al. 2018), water and sediments (Adeogun et al. 2015), atmospheric aerosols (Philip et al. 2018). PAEs are classified as endocrine disrupting chemicals (EDCs) due to their estrogenic and endocrine disrupting properties, which may cause fertility problems (Latini et al. 2006; Mathieu-Denoncourt et al. 2015), respiratory diseases, childhood obesity, abortion, and neuropsychological disorders (Stojanoska et al. 2017). Six of PAEs, including dimethyl phthalate (DMP), diethyl phthalate (DEP), dibutyl phthalate (DBP), dinoctyl phthalate (DOP), diethylhexyl phthalate (DEHP), and butyl benzyl phthalate (BBP) have been listed as the priority pollutants by the United States Environmental Protection Agency (USEPA), the European Union (EU), and the China National Environmental Monitoring Center (US EPA 1992; European Union 1993; Xu et al. 2005).

Conventional available methods for removing PAEs include biodegradation, advanced oxidation (Tichonovas et al. 2017) and photocatalysis (You et al. 2018), and biodegradation is considered to be an efficient, low-cost, safety and stability method (Gao et al. 2016). In the past 40 years, lots of PAEs-biodegrading bacteria, mainly belonging to genera Pseudomonas, Arthrobacter, Comamonas, Gordonia, Rhodococcus, and Sphingomonas, have been isolated from water, sediment, soil, etc., but microbial resources of high-efficiency and applicable strains were limited (Wang et al. 2003; Wu et al. 2011; Ren et al. 2018; Shen et al. 2019). Although Microbacterium sp. strains were reported to remove DEHP and DBP (Chen et al. 2007; Lu et al. 2020), few studies on the mechanism and genomic analysis of Microbacterium sp. were found up to now.

The present work described the isolation and identification of a DBP-biodegrading Microbacterium sp. USTB-Y, which could transformed DBP to PA. It explored the mechanism of biodegradation and characterized the environmental factors influencing the degradation process. In addition, we analyzed the whole genome shotgun sequencing to putatively assign genes expected to be involved in PAEs metabolism, and also proposed the reason for why Microbacterium sp. USTB-Y was unable to degrade PA.

\section{Materials And Methods Chemicals and culture medium}

DMP, DEP, DBP, BBP, DEHP, DOP, monoethyl phthalate (MEP), monomethyl phthalate (MMP), monobutyl phthalate (MBP), phthalic acid (PA), protocatechuic acid (PCA) and butanol (analytical grade, above $98 \%$ of purity) used for biodegradation experiments was purchased from Aladdin Chemistry Co. (Shanghai, China). Standard stock solution of PAEs in methanol was prepared. All organic solvents used were of HPLC grade, while other reagents were of analytical grade.

Improved Luria-Bertani (LB) medium contained (g/L) $\mathrm{NaCl}$ (10), beef peptone (10), yeast extract (5), glucose (5) and its final pH was adjusted to 7.5 .

Mineral salt medium (MSM) contained (g/L) NH $4 \mathrm{Cl}(0.5), \mathrm{Na}_{2} \mathrm{HPO}_{4}(0.3), \mathrm{KH}_{2} \mathrm{PO}_{4}(0.05), \mathrm{MgSO}_{4}(0.1), \mathrm{CaCl}_{2}$ (0.01), ammonium ferric citrate (0.01), 0.5 mL trace elements (Karn et al., 2010), and its final pH was adjusted to 7.5. The media and vessels (e.g., Erlenmeyer flask) were sterilized in an autoclave at $121^{\circ} \mathrm{C}$ for $20 \mathrm{~min}$.

\section{Enrichment and isolation of DBP biodegrading bacteria}

Activated sludge samples were collected from Weifang Kangda sewage treatment factory of Shandong in China. Standard stock solution of DBP was added to a 250-mL triangular flask and the solvent methanol was allowed to evaporate overnight before adding $50 \mathrm{~mL}$ MSM and 10 grams of activated sludge. These flasks were incubated at $30^{\circ} \mathrm{C}$ and $200 \mathrm{rpm}$. An aliquot of $5 \mathrm{ml}$ was subcultured to fresh medium every week, the concentration of DBP increasing from 50 to $1000 \mathrm{mg} / \mathrm{L}(50,100,200,400,600,800$, and $1000 \mathrm{mg} / \mathrm{L})$. After 7 weeks, some bacteria could grow in the medium with $1000 \mathrm{mg} / \mathrm{L} \mathrm{DBP}$; then serial dilutions of the final bacterial culture were conducted and inoculated with spread method onto the LB agar plates and cultured for $48 \mathrm{~h}$ at $30^{\circ} \mathrm{C}$. Different isolates were screened by biodegradation ability of DBP, and a promising bacterial strain USTB-Y was isolated and used.

\section{Identification and characterization, whole genome sequencing of strain USTB-Y}

The morphology of strain USTB-Y was observed by a microscope (OLYMPUS DP72, Japan). Total DNA was extracted from the purified bacterium using the Bacterial Genome Extraction kit (Tiangen, Beijing) following the manufacturer's instructions. Following centrifugation, the supernatant was used as template 
for polymerase chain reaction (PCR) with the primer pair of 27F (5'-AGAGTTTGATCCTGGCTCAG-3') and 1492R (5'-GGTTACCTTGTTACGACTT-3') (48). The PCR products were sequenced by Shenggong Biotechnology Co., Ltd. (Shanghai, China) and deposited in the GenBank database under the accession number MW828316. The resulting sequence of strain USTB-Y were aligned and compared with the known gene sequences in EzBioCloud database. The nearest neighbor sequences were aligned using Clustal W, and a phylogenetic tree based on the 16S rDNA sequence data was constructed by the neighbor-joining method with MEGA 7 software. To define the phylogenetic relationship, the genome sequences of available Microbacterium sp. strains in EzBioCloud database were downloaded from NCBI and whole genome average nucleotide identity (ANI) values were obtained from pairwise comparison online (EzBioCloud database).

The draft genome was sequenced by Illumina NovaSeq platform of Beijing Fixgene Co., Ltd. Low reads were trimmed by fastp software. High quality reads were then assembled by Spades software. The genome sequence was annotated by the PGAP on NCBI (October, 2020). The sequence data were submitted to NCBI Sequence Read Archive (https://www.ncbi.nlm.nih.gov/sra/ ) with SRA number SRR14179763.

\section{Inoculum preparation}

Strain USTB-Y was pre-cultured in LB liquid medium at $30^{\circ} \mathrm{C}$ and $200 \mathrm{rpm}$ for $18 \mathrm{~h}$ (at logarithmic phase), and cell pellets were harvested by centrifugation $(6000 \mathrm{rpm}$ for $10 \mathrm{~min})$, washed three times with sterile physiological saline water and re-suspended in $\mathrm{MSM}$ to obtain the inoculum suspension $\left(\mathrm{OD}_{600}=1.8\right.$, tested by SHIMADZU UV-2450 spectrophotometer, approximately $1.2 \times 10^{9} \mathrm{CFU} / \mathrm{mL}$ determined by colony counting method), and $2 \%$ of inoculation proportion (volume ratio) was used in all the biodegradation experiments.

\section{Optimization of DBP degradation conditions}

The biodegradation experiments were performed in $20 \mathrm{~mL}$ MSM supplementing with $50 \mathrm{mg} / \mathrm{L}$ DBP in triplicates and cultured at $200 \mathrm{rpm}$ and $30^{\circ} \mathrm{C}$ for $24 \mathrm{~h}$. In this experiment, three single factors including $\mathrm{pH}$, temperature and initial concentrations were used as independent variables to investigate their effects on the biodegradation ratios of DBP by USTB-Y. The $\mathrm{pH}$ of culture medium was set at $5.5,6.5,7.5,8.5$ and $9.0\left(30^{\circ} \mathrm{C}\right.$, initial concentration of $\mathrm{DBP}$ at $\left.50 \mathrm{mg} / \mathrm{L}\right)$; temperature at $15,25,30,37$ and $40^{\circ} \mathrm{C}(\mathrm{pH}$ at 7.5 , initial concentration of DBP at $50 \mathrm{mg} / \mathrm{L})$; and initial concentrations of DBP at $50,100,500$ and $1000 \mathrm{mg} / \mathrm{L}$ $\left(\mathrm{pH}\right.$ at $\left.7.5,30^{\circ} \mathrm{C}\right)$.

\section{Substrate utilization tests}

Liquid MSM of $20 \mathrm{~mL}$ was supplemented with each compound of PA, PCA, MMP, MEP, MBP, DMP, DEP, DBP, DOP, DEHP and BBP (50 mg/L) as the sole carbon source to test the substrate utilization of strain USTB-Y. After culturing at optimal condition for $72 \mathrm{~h}$, the residual of these compounds in the culture was analyzed by HPLC (Dionex Ultimate 3000, Thermo Fisher Scientific Inc., USA) after 72 h, respectively.

\section{Biodegradation Kinetic of DBP by Microbacterium sp. USTB-Y}

To investigate biodegradation kinetic of DBP by whole cells of strain USTB-Y, $20 \mathrm{~mL}$ MSM with initial concentration of 50, 100,500 and $1000 \mathrm{mg} / \mathrm{L}$ were prepared in triplicates, respectively. DBP biodegradation experiments were carried out under the optimum conditions in dark for $5 \mathrm{~d}$, and samples of culture solution were collected at regular intervals. Non-inoculated medium served as a control.

\section{Biodegradation of DBP by cell-free extracts solution}

For measurement of enzymatic degrading activity, supernatant of cell-free extracts was prepared. After cultured in $1000 \mathrm{mg} / \mathrm{L}$ DBP-MSM for $96 \mathrm{~h}$, cells were sedimented by centrifugation ( $6000 \mathrm{rpm}, 15 \mathrm{~min}$ ). The biomass (about $0.7 \mathrm{~g}$ of wet weight) was used to prepared $7 \mathrm{~mL}$ cell-free extracts using M5 Bacterial Protein Extraction Kit purchased from Mei5 Biotechnology, Co., Ltd (China). Cell debris was removed by centrifugation ( $4^{\circ} \mathrm{C}, 12000 \mathrm{rpm}$ and $\left.15 \mathrm{~min}\right)$. After filtered with $0.22 \mu \mathrm{m}$ organic nylon micropore membrane, $200 \mu \mathrm{L}$ supernate of cell-free extracts was added into $10 \mathrm{~mL}$ of $100 \mathrm{mg} / \mathrm{L}$ DBP-PBS (phosphate buffer saline, $0.05 \mathrm{M}, \mathrm{pH}=7.4$ ) and cultured at $200 \mathrm{rpm}$ and $30^{\circ} \mathrm{C}$, and PBS without cell-free extracts supernate was as a control. Samples at $0,2,4,8$ and $12 \mathrm{~h}$ were collected and treated for HPLC analysis.

\section{Analysis of residual substrates by HPLC}

HPLC was used to determine the concentrations of DBP and their metabolites followed an improved method described by Lu et al. (2020). Twice the volume of methanol was added to the culture or the enzyme assay solution, and the mixture was vortexed for 5 min before it was centrifuged at 10000 rpm for 5 min, then the supernatant was filtered through a $0.22 \mu \mathrm{m}$ organic nylon micropore membrane and analyzed by an Dionex Ultimate $3000 \mathrm{HPLC}$ (Thermo Fisher Scientific Inc., USA) which was equipped with a C18 reverse phase column ( $250 \times 4.6 \mathrm{~mm}^{2}, 5 \mu \mathrm{m}$ particle size, Dikema Technology Co. Ltd., China), and a UVdetector at $228 \mathrm{~nm}$. For DBP analysis, methanol and an aqueous solution of $0.5 \%$ acetic acid $(80: 20, \mathrm{v} / \mathrm{v})$ were used as the mobile phase with a flow rate of $1.0 \mathrm{~mL} / \mathrm{min}$. The temperature of column oven was $30^{\circ} \mathrm{C}$. For quantification, an external standard method was applied and the standard curve was built following a six-point calibration curve (ranged from 25 to $500 \mathrm{mg} / \mathrm{L}$, and the $\mathrm{R}^{2}$ was above 0.99 ). All experiments were conducted in triplicates and were subjected to statistical analysis.

\section{Identification of biodegradation products by GC-MS}

Liquid MSM with $100 \mathrm{mg} / \mathrm{L}$ of DBP was inoculated with strain USTB-Y and cultured at $200 \mathrm{rpm}$ under the optimal conditions. The culture samples were collected at $0,4,10$ and $12 \mathrm{~h}$, respectively. All treatments were in triplicates and non-inoculation served as the control. HPLC analysis followed the method described above. For GC-MS analysis, cultured solution was extracted twice with equal volume of dichloromethane, and the combined organic phase was concentrated to near dryness by a rotary evaporator, and then the residue was redissolved in acetone for GC-MS (QP2010 Plus, Shimadzu, Japan) analysis. A capillary column (HP-5MS, $0.25 \mu \mathrm{m} \times 0.25 \mathrm{~mm} \times 30 \mathrm{~m}$ ) was used for separation. Helium ( $>99.99 \%$ of purity) was employed as carrier gas at a flow rate of 1.0 $\mathrm{mL} / \mathrm{min}$. The temperatures of injection and ion source were set at $250^{\circ} \mathrm{C}$ and $220^{\circ} \mathrm{C}$, respectively. The $\mathrm{GC}$ oven temperature was programmed as follows: 
$100^{\circ} \mathrm{C}$ held for $2 \mathrm{~min}$, raised at $15^{\circ} \mathrm{C} / \mathrm{min}$ to $129^{\circ} \mathrm{C}$, then at $40^{\circ} \mathrm{C} / \mathrm{min}$ to $280^{\circ} \mathrm{C}$ (held for $5 \mathrm{~min}$ ). The extract $(1 \mu \mathrm{L}$ ) was injected in the splitless mode. Mass spectra were acquired in the electron ionization (EI) mode using an electron impact ionization of $70 \mathrm{eV}$ and scanning at 45-500 amu.

\section{Bioremediation of DBP artificially contaminated soil by strain USTB-Y}

Soil samples were taken from top $20 \mathrm{~cm}$ of soil profile on a botanical garden in Weifang and contained no detectable residual PAEs. The soil was mixed thoroughly, sieved through 2-mm mesh to remove stones and debris, and stored at room temperature overnight. Soil properties were measured as follows: $\mathrm{pH}$ 6.83 , organic carbon $15.4 \mathrm{~g} / \mathrm{kg}$, total nitrogen $1.63 \mathrm{~g} / \mathrm{k}$, total phosphorus $0.79 \mathrm{~g} / \mathrm{kg}$, total potassium $13.75 \mathrm{~g} / \mathrm{kg}$. Soil samples were autoclaved and treated with DBP thoroughly to get a concentration of $50 \mathrm{mg} / \mathrm{kg}$ dry soil, and followed by methanol evaporation for $12 \mathrm{~h}$ at room temperature.

Prepared soil of $50 \mathrm{~g}$ was put into $150 \mathrm{~mL}$ glass bottles sealed with a gas-permeable membrane, and inoculated with the prepared inoculum to give an initial bacterial population of $6 \times 10^{7} \mathrm{CFU} / \mathrm{g}$ as the biodegradation treatment. All soil samples were cultured at $30^{\circ} \mathrm{C}$ in the dark for $12 \mathrm{~h}$. DBP-contaminated soil without inoculation served as a blank control and all treatments were prepared in triplicate. Soil samples of $2 \mathrm{~g}$ were collected and soaked with $20 \mathrm{~mL}$ of a mixture of acetone and hexane $(1: 1, \mathrm{v} / \mathrm{v})$ overnight in a glass centrifuge bottle, and then extracted ultrasonically three times to collect organic phase. After centrifugation at $6000 \mathrm{rpm}$ for $10 \mathrm{~min}$, the supernate solution was concentrated to near dryness with a rotary evaporator. The residue was redissolved in $5 \mathrm{~mL}$ methanol, which was diluted to a suitable concentration for HPLC analysis.

\section{Statistics analyses}

The data were calculated, analyzed and plotted by Microsoft Excel 2010 (Microsoft Co., USA).The degradation rate of DBP was calculated by Eq. (1):

Degradation rate $(\%)=\left(C_{0}-C_{t}\right) / C_{0} \times 100 \%(1)$

Where $\mathrm{C}_{0}$ is the initial concentration of DBP in culture (or soil), and $\mathrm{C}_{t}$ is the residual concentration of DBP after biodegradation experiment.

The biodegradation process of DBP was confirmed by first-order kinetic model as Eq. (2), the half-life of first-order reaction could be calculated by Eq. (3) (Suzuki et al. 1998; Heo et al. 2020):

$\ln C=-k t+A(2)$

$t_{1 / 2}=\ln 2 / k(3)$

Where $\mathrm{C}$ is the DBP concentration ( $\mathrm{mg} / \mathrm{L}$ ) at time $\mathrm{t}(\mathrm{h}), \mathrm{k}$ is the first-order kinetic constant $\left(\mathrm{h}^{-1}\right)$, and $\mathrm{A}$ is a constant. $\mathrm{t}_{1 / 2}$ is the half-life corresponding to the time interval of the DBP concentration to decrease to half of its initial value.

\section{Results}

\section{Isolation and identification of the bacterial strain USTB-Y}

Strain USTB-Y capable of utilizing DBP as the sole carbon and energy source was isolated from activated sludge. On a LB plate, its colonies were regular round, opaque, smooth and glossy surface, and turned to yellow after $72 \mathrm{~h}$. The morphological examination under the light microscope revealed short rods cells (Online Resource1, Fig. S1-1). The physiological and biochemical assays indicated that strain USTB-Y was a Gram-positive strain, capable of producing catalase and starch hydrolase (Online Resource1, Table S1-1). Strain USTB-Y was deposited in culture collection of CGMCC (China General Microbiology Culture Collection Center, No: 1.18977). The 16S rDNA gene sequence (1393 bp) of strain USTB-Y was searched against the EzBioCloud database. It showed 99.14\% identity to Microbacterium azadirachtae DSM 23848 (T). Phylogenetic analyses based on 16S rDNA sequences within genus Microbacterium suggested strain USTB-Y was closest to the species Microbacterium panaciterrae DCY56 (T) (Fig. 1). Whole genome average nucleotide identity (ANI) values were obtained from pairwise comparison of the available genome sequences in the genus Microbacterium. ANI values between USTB-Y and the members of genus Microbacterium were in the range of 74.98-87.25\% (Online Resource1, Table S1-2). Nine nearby neighbor species to strain USTB-Y were chosen to phylogenetic tree analysis on the basis of the whole genome sequences by using OAT. The result revealed that strain USTB-Y shared highest identities (86.61\%) to Microbacterium azadirachtae DSM 23848 (Fig. 2). According to current bacterial taxonomy, strain USTB-Y is a potential novel species within Microbacterium genus when their average nucleotide identity (ANI) < 95\% (Kim et al. 2014).

The growth of strain USTB-Y and the biodegradation rate of DBP were analyzed and compared between that in liquid mineral salts medium (MSM) with 1000 $\mathrm{mg} / \mathrm{L} \mathrm{DBP}$ as the sole carbon source, and in a medium without DBP. Strain USTB-Y grew rapidly in the first $72 \mathrm{~h}$ of cultivation (Fig. 3 ); the peak value appeared at $96 \mathrm{~h}$ and decreased gradually thereafter. The degradation rate of DBP increased in the first $96 \mathrm{~h}$ and subsequently declined. This might be due to the decline of USTB-Y and its degradation ability. It might also be that the degradation products from DBP hindered the further biodegradation of DBP by USTB-Y. At $96 \mathrm{~h}$, DBP residue in the culture medium was $19.26 \mathrm{mg} / \mathrm{L}$ and the biodegradation rate was $98.07 \%$. In the sterile control, the degradation rate of $\mathrm{DBP}$ was $0.90 \%$. This indicated that strain USTB-Y could grow with DBP as a carbon source.

\section{Effects of culture conditions on DBP biodegradation by strain USTB-Y}

Figure 4 shows effects of culture conditions (temperature, $\mathrm{pH}$ and different initial concentrations) on the biodegradation ratios of $\mathrm{DBP}(50 \mathrm{mg} / \mathrm{L})$ by strain USTB-Y. DBP biodegradation ratios were significantly different among tested temperatures in range of $15^{\circ} \mathrm{C}-40^{\circ} \mathrm{C}(\mathrm{Fig} .4 \mathrm{a})$, and it was higher than $96 \%$ both at $25^{\circ} \mathrm{C}$ and $30^{\circ} \mathrm{C}$, but declined to $58 \%, 59 \%$ and $48 \%$ when culture temperature was 15,37 and $40^{\circ} \mathrm{C}$, respectively. These results imply that the optical temperature for DBP biodegradation by strain USTB-Y was $30^{\circ} \mathrm{C}$. DBP biodegradation percentages were not significantly different in range of 5.5 to 9.5 , and they were all higher than 95\% (Fig. 4b), which implied that neutral pH was more suitable for strain USTB-Y to biodegrade DBP. Additionally, DBP 
biodegradation ratios at $24 \mathrm{~h}$ were almost $100 \%$ with the initial concentrations of 50 and $100 \mathrm{mg} / \mathrm{L}$, while it declined to $51.6 \%$ and $23.8 \%$ with the initial concentrations of 500 and $1000 \mathrm{mg} / \mathrm{L}$, respectively (Fig. 4c). High concentration of DBP (500 and $1000 \mathrm{mg} / \mathrm{L}$ ) were biodegraded with longer time (72 h) by

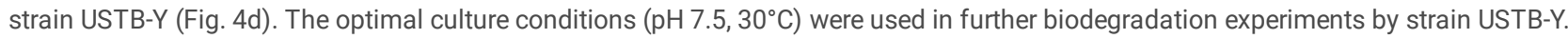

\section{Biodegradation kinetics of DBP in MSM}

The dynamic curve of DBP biodegradation is illustrated in Fig. 5. The biodegradation ratios of DBP were evidently dependent on the initial concentrations to some degree. DBP could be rapidly biodegraded by this strain up to $1000 \mathrm{mg} / \mathrm{L}$. When DBP concentration was 50 and $100 \mathrm{mg} / \mathrm{L}$, DBP was almost completely removed by strain USTB-Y within 10 and 12 h, respectively (Fig. 5a). After 72 h, DBP concentration in culture media almost removed by 97.4 and $91.4 \%$ for 500 and $1000 \mathrm{mg} / \mathrm{L}$, respectively (Fig. $5 b)$. Results showed that DBP biodegradation fit well with first-order kinetics $\left(R^{2}>0.9\right)$. When DBP initial concentrations were 50 and $100 \mathrm{mg} / \mathrm{L}$, the first-order biodegradation constant $(k)$ was 0.3331 and $0.393 \mathrm{~h}^{-1}$, and the $\mathrm{t}_{1 / 2}$ was 3.61 and $3.35 \mathrm{~h}$, respectively. When the initial concentrations of DBP were increased to 500 and $1000 \mathrm{mg} / \mathrm{L}$, the first-order degradation constant $(k)$ fell to 0.0607 and $0.0628 \mathrm{~h}^{-1}$ with the half-life increasing to 21.00 and $24.71 \mathrm{~h}$, respectively (Online Resource 1, Table S1-3). The biodegradation rate of DBP was dose-dependent and the initial concentration of DBP may play an important role in the biodegradability of DBP.

\section{Substrate utilization of strain USTB-Y}

The degradation of individual PAEs (DMP, DEP, DBP, DOP, BBP, and DEHP) and most commonly detected intermediates of PAEs (MMP, MEP, MBP, PA, and PCA) were measured (Fig. 6). Strain USTB-Y could biodegrade tested dialkyl PAEs with shorter alkyl-chains, such as DMP, DEP, DBP and BBP; but hardly removed tested dialkyl PAEs with longer alkyl-chains, such as DEHP and DOP (removal rate $<5 \%$, data was not shown). For tested intermediates, it showed relatively higher removal rate against MBP (100\%) and MEP (79\%) but showed lower biodegrading efficiency against MMP (26.6\%), and hardly remove PA and PCA (removal rate $<5 \%$, data was not shown). In additional, strain USTB-Y could not grow on $1 \mathrm{~g} / \mathrm{L}$ PA or butanol (the aliphatic product of the putative esterase that hydrolizes DBP) as sole carbon source.

\section{Identification and bioconversion analysis of DBP biodegradation product}

Both of the whole cells and crude enzyme solutions from strain USTB-Y showed high biodegrading efficiency against DBP (Fig. 3 and Online Resource1 Fig. S1-2). HPLC chromatograms (Fig. 7) of cells culture samples showed that DBP (retention time at 11.925 min) was completely removed and a product (retention time at $4.17 \mathrm{~min}$ ) was accumulated in the end. It indicated that the intra-cellular hydrolytic enzymes initiated the pathway and transformed DBP to another compound, whose retention time was same with the PA standard (data was not show). The product was further identified by GC-MS (Fig. 8). By comparing with the authentic standard solution and the published mass spectra from National Institute of Standards and Technology database (NIST14s library), the compound $\otimes$ at $0 \mathrm{~h}$ and $10 \mathrm{~h}$ sample was $\mathrm{DBP}$, and the compound $\otimes$ at $10 \mathrm{~h}$ was corresponding to phthalic acid (PA). The peak around position 33 min is a polymer, which is both appeared at $0 \mathrm{~h}$ and $10 \mathrm{~h}$.

As shown in Fig. 9, the concentration of PA as the initial intermediate of DBP increased, whereas the concentration of DBP decreased, indicating a progressive bioconversion of DBP to PA by strain USTB-Y (similar with the enzymolysis by cell-free extracts). DBP with $100 \mathrm{mg} / \mathrm{L}$ was biodegraded completely in $12 \mathrm{~h}$, and the concentration of PA reached $46.85 \mathrm{mg} / \mathrm{L}$ in the liquid medium and almost no change occurred after approximately $7 \mathrm{~d}$ (data not shown). In the control group without strain USTB-Y, the concentration of DBP was shown to be constant. In addition, with the proceeding of DBP biodegradation, pH of the medium solution was gradually declined from 7.31 to 6.84 , which indicated that the accumulation of acidic compound(s) (such as PA).

\section{Overview of genome analysis and molecular mechanism for DBP biodegradation}

The draft genome was sequenced using the Illumina Hiseq platform with a paired-ends sequencing. It revealed a total length of 4109641 bp, with an average coverage depth exceeding 100x and an average GC content of 70.67\% (Tables S4). The reads were assembled into 20 scaffolds with a N50 of 745149 bp. Genome properties and statistics of strain USTB-Y were listed in Online Resource1 Table S1-4. Out of the total 3922 predicted genes, there were 3807 proteincoding genes, 56 pseudogenes, 43 tRNA genes, 3 noncoding RNA (ncRNA), and 3 rRNA operons in the genome.

The results of genome annotation showed that $81.59 \%$ of genes (3200) were assigned to 20 different categories of COG (Online Resource1, Fig. S1-3). The genes number of carbohydrates transport and metabolism (G), secondary metabolites biosynthesis, transport and catabolism (Q), and intracellular trafficking, secretion, and vesicular transport function (U), were 268,58 and 30, respectively. According to the KEGG analysis 75 genes were involved in the Xenobiotics biodegradation and metabolism, among which $25,13,26$, and 9 genes were predicted to participate in benzoate metabolic pathway, biodegradation of aromatic compounds, phenylalanine metabolism, and aminobenzoate degradation, respectively (Online Resource1 Fig. S1-4, Online Resource 2 and 3).

In the present study, Microbacterium strain USTB-Y was found to be able to convert DBP to PA. According to NR analysis, there were 29 and 188 genes encoding for putative esterase/carboxylesterase and hydrolase/alpha/beta hydrolase, respectively (Online Resource 4). Among these genes encoding for esterases or hydrolases, gene3780 and gene3781 showed 100\% identity with $\mathrm{mpeH}$ (GenBank accession no. MK165157) and dpeH(GenBank accession no. MK165156) from Microbacterium sp. PAE-1, respectively (Lu et al. 2020), and it reported that DpeH could only hydrolyze DBP to MBP, while MpeH could only hydrolyze MBP to PA. But no phthalate catabolic gene cluster (pht) was identified in the genome of strain USTB-Y. Besides, there were no enzymes annotated to participate in the phthalate biodegradation in the pathway map of biodegradation of aromatic compounds in KEGG (Online Resource 5). These results elucidated the molecular mechanism for inability to degrade PA in strains USTB-Y.

\section{Bioremediation of DBP artificially contaminated by strain USTB-Y}

Figure 10 showed the biodegradation of DBP by strain USTB-Y in soil. DBP at initial concentration of $50 \mathrm{mg} / \mathrm{kg}$ decreased sharply by $100 \%$ in the biodegradation treatment but did not change remarkably in the control (about 11\%) within $12 \mathrm{~h}$. The removal percentage of DBP in the treatment inoculated 
with strain USTB-Y was significantly higher by $89 \%$ than the control (without inoculation) after $12 \mathrm{~h}$ of incubation. This result indicated that USTB-Y could remove DBP efficiently in artificially contaminated soil.

\section{Discussion}

The genus Microbacterium was characterized as Gram-stain positive, asporogenous and rod-shaped with optimum growth observed at $20-30^{\circ} \mathrm{C}$ (Suzuki et al. 1998), and distributes extensively in various environments including soil, seawater, air, faeces, rhizosphere, compost and sediment (Heo et al 2020). Members of genus Microbacterium were reported to biodegrade various organic contaminants such as crude-oil (Schippers 2005), sulfonamide antibiotics (Ricken et al. 2015), carbendazim (Lei et al. 2017), benzo [a] pyrene and pyrene (Qin et al. 2017), PAHs (Cazals et al. 2019), decabromodiphenyl ether (Yu et al. 2019), etc. In 2007, Chen et al. first reported that Microbacterium sp. CQ0110Y could biodegrade DEHP (Chen et al. 2007). Yang et al. reported that a stable DBP-degrading bacterial consortium B1 was mainly composed of Pandoraea sp. and Microbacterium sp. (Yang et al. 2018). In this study, a newly isolated Microbacterium sp. USTB-Y from activated sludge could efficiently transformed DBP into PA, and removed DMP, DEP, DBP and BBP in MSM, which is consistent with the results of Microbacterium sp. PAE-1 (Lu et al., 2020).

Strain USTB-Y could easily remove tested dialkyl PAEs with shorter alkyl-chains (DMP, DEP, DBP and BBP); but hardly remove tested dialkyl PAEs with longer alkyl-chains (DEHP and DOP). It may be due to biodegradability differences in short-versus long-chain PAEs, and the steric effects of long phthalate ester side chains avoid the binding of hydrolytic enzymes to phthalate, thereby inhibiting their hydrolysis (He et al. 2013; Liang et al. 2008).

For tested intermediates, it showed relatively higher removal rate against MBP and MEP but lower biodegrading efficiency against MMP, and hardly removed/utilized PA, PCA and butanol. It indicated that DBP was possibly removed via MBP or partial MEP, and PA or PCA couldn't be biodegraded by strain USTB-Y.

Strain USTB-Y could biodegrade DBP at a broad range of temperatures $\left(15-40^{\circ} \mathrm{C}\right)$ and $\mathrm{pH}(5.5-9.5)$, and better adapted to low temperature and acidity. Both the degradation ratios at $15^{\circ} \mathrm{C}$ and pH 5.5 reached more than $58 \%$ (Fig. 4), higher than that of consortium B1 (Yang et al. 2018 ) and consortium LV- 1 (Wang et al. 2017). In this study, Microbacterium sp. USTB-Y could biodegrade almost all DBP of $100 \mathrm{mg} / \mathrm{L}$ within $12 \mathrm{~h}$, far higher than that by bacterial consortium LV1 (Wang et al. 2017), Gordonia sp. Strain QH-12 (Jin et al. 2016), and Bacillus subtilis N-1 (Huang et al. 2018) (100\% within 3 d, 100\% within 20 h, and 100\% within $5 \mathrm{~d}$, respectively). DBP degradation constants (0.0607-0.3331 $\mathrm{h}^{-1}$ with half-life of 3.61-24.71 h for 50-1000mg/L of DBP) by strain USTB-Y was far higher than those obtained by endphytic Bacillus subtilis N-1 (0.0122-0.0959 $\mathrm{d}^{-1}$ with half-life of 7.23-56.8 h for 100-200mg/L of DBP) (Huang et al. 2018), Sphingobium yanoikuyae SHJ (0.1867 $\mathrm{d}^{-1}$ with half-life of $101.4 \mathrm{~h}$ for $50 \mathrm{mg} / \mathrm{L}$ of DBP) (Feng et al. 2018), Providencia sp. 2D (0.0265-0.0800 d ${ }^{-1}$ with halflife of 8.66-26.16 h for 50-1000 mg/L of DBP) (Zhao et al. 2018). Figure 10 showed that strain USTB-Y could remove $50 \mathrm{mg} / \mathrm{L}$ DBP from artificially contaminated soil within $12 \mathrm{~h}$ which was much better than the removal of DBP by Bacillus subtilis N-1 ( $5 \mathrm{~d}$ ) and Rhodococcus ruber CQ0301 (10 d) (Huang et al. 2018; Li et al. 2006). It suggested that this strain has great potential in bioremediation of DBP artificially contaminated soil.

PAEs biodegradation could be divided into two steps: transformation of PAEs into PA and utilization of PA. The bacterial biodegradation of DBP entailed sequential hydrolysis of the ester bonds between the alkyl chains and the aromatic ring, involving the formation of MBP (hydroxylation) or DEP ( $\beta$-oxidation) followed by PA or direct formation of PA (Cazals et al. 2019; Huang et al. 2018), then the aromatic ring cleavage occurred before entering the TCA cycle (Lei et al. 2017; Feng et al. 2018; Zhao et al. 2018). In this study, PA was identified as the end-product of DBP in the biodegradation both by cells and free-cell supernate, and the other metabolites such as DMP, DEP etc. were not detected, probably because they had disappeared owing to immediate degradation by strain USTB-Y once they were formed. It also indicated that intracellular hydrolases catalyzed DBP biodegradation or transformation in strain USTB-Y.

Several enzymes and their encoding genes involved in PAEs biodegradation have been reported, especially PAEs hydrolase (Wu et al. 2013; Chen et al. 2015; Iwata et al. 2016; Nahurira et al. 2017). Two esterase/hydrolase genes named $d p e H$ and $m p e H$, located in the same transcription unit, were cloned from Microbacterium sp. PAE-1 by Lu et al. in 2020. DpeH could only hydrolyze dialkyl PAEs to the corresponding monoalkyl PAEs, which were then hydrolyzed to PA by MpeH. In this study, it was confirmed that gene3780 and gene3781 from strain USTB-Y showed $100 \%$ identity with $m p e H$ and $d p e H$ from Microbacterium sp. PAE-1, respectively (Online Resource1, Table S1-5 and Fig. S1-5). These findings provided biological information base for bioconversion of DBP into PA by strain USTB-Y, which is helpful in understanding the molecular mechanism of PAEs biodegradation in Microbacterium sp.

It is well known that PA could be converted to PCA by phthalate catabolic gene cluster (pht) (Li et al. 2016). In general, the whole pht cluster consisted of seven functional genes ( $p h t A a A b A c A d B C R$ ) and an unknown ORF ( $p h t U$ ). Of the seven functional genes in Gram-positive bacteria, phtAaAbAcAd genes encode dioxygenase which can oxygenate phthalate to 3, 4-dihydro-3, 4-dihydroxyphthalate, and then 3, 4-dihydro-3,4-dihydroxyphthalate was dehydrogenated to 3,4dihydroxyphthalate by dehydrogenase ( $p h t B$ ) and finally 3,4-dihydroxyphthalate was decarboxylated to form protocatechuate by decarboxylase ( $p h t C$ ). In this study, the reported pht genes were not found in the draft genome of strain USTB-Y (S4), and there were no enzymes annotated to participate in the pathway map of degradation of aromatic compounds in KEGG (S5). Besides Microbacterium sp. USTB-Y, Microbacterium sp. PAE-1 was also reported to be unable to utilize PA. The reason for this phenomenon may be attributed to gene lacking. Construction of genetically engineered bacteria can overcome the incomplete degradation of phthalate esters during bioremediation process. Further experiments have to be carried out to elucidate this possibility

\section{Conclusions}

Microbacterium sp. USTB-Y is a high efficient bacterium for removing DBP. It could remove $100 \%$ of DBP of $50 \mathrm{mg} / \mathrm{L}$ both in MSM and in DBP artificially contaminated soil within $12 \mathrm{~h}$. The optimal conditions for the strain were $30^{\circ} \mathrm{C}$ and $\mathrm{pH} 7.5$. The end-product of DBP was further investigated using HPLC and GC/MS and PA was identified. Importantly, the draft genome analysis revealed that many genes in strain USTB-Y encoded hydrolases involved in transforming 
DBP into PA, especially gene3871 and gene3870. This study is helpful to the development of microbe resources for DBP removal and the understanding on genetic mechanisms of DBP biodegradation in Microbacterium sp. strains.

\section{Declarations}

Tobe used for all articles, including articles with biological applications $\square$

\section{Funding}

This work was supported by the National Natural Science Foundation of China (21677011) and the Fundamental Research Funds for the Central Universities (F MP-20-39).

\section{Conflict of interest}

The authors declare that there is no conflict of interest.

\section{Availability of data and material}

The datasets used or analyses during the current study are available from the corresponding author on reasonable request

\section{Author contributions}

$\mathrm{ZZ}$ and $\mathrm{HY}$ conceived and designed the experiments. ZZ performed the experiments. $\mathrm{CL}$ and SA were involved in sample preparation. QX, AA, HZ, YL and YP W€ by $Z Z$, reviewed and edited by HY.

Ethics approval Not applicable.

Consent to participate Not applicable.

Consent for publication Not applicable.

\section{Acknowledgments}

This work was supported by the National Natural Science Foundation of China (21677011) and the Fundamental Research Funds for the Central Universities (PRF-MP-20-39).

\section{References}

1. Adeogun AO, Ibor OR, Omogbemi ED, Chukwuka AV, Adegbola RA, Adewuyi GA, Arukwe A (2015) Environmental occurrence and biota concentration of phthalate esters in Epe and Lagos Lagoons, Nigeria. Marine Environmental Research 108: 24-32. https://doi.org/10.1016/j.marenvres.2015.04.002

2. Benjamin S, Pradeep S, Josh MS, Kumar S, Masai E (2015) A monograph on the remediation of hazardous phthalates. Journal of Hazardous Materials 298: 58-72. https://doi.org/10.1016/j.jhazmat.2015.05.004

3. Cazals F, Huguenot D, Crampon M, et al (2019) Production of biosurfactant using the endemic bacterial community of PAHs contaminated soil, and its potential use for PAHs remobilization. Science of the Total Environment: 136143. https://doi.org/10.1016/j.scitotenv.2019.136143

4. Chen JA, Li X, Li J, Cao J, Qiu ZQ, Zhao Q, Xu C, Shu WQ (2007) Degradation of environmental endocrine disruptor di-2-ethylhexyl phthalate by a newly discovered bacterium, Microbacterium sp. strain CQ0110Y. Applied Microbiology and Biotechnology 74: 676-682. https://doi.org/10.1007/s00253-0060700-3

5. Chen X, Zhang XL, Yang Y, Yue, DM, Xiao L, Yang LY (2015) Biodegradation of an endocrine-disrupting chemical di- $n$-butyl phthalate by newly isolated Camelimonas sp. and enzymatic properties of its hydrolase. Biodegradation 26: 171-182. https://doi.org/10.1007/s10532-015-9725-6

6. Daiem MMA, Rivera-Utrilla J, Ocampo-Pérez R, Mendez-Diaz JD, Sanchez-Polo M (2012) Environmental impact of phthalic acid esters and their removal from water and sediments by different technologies-A review. Journal of Environmental Management 109: 164-

178. https://doi.org/10.1016/j.jenvman.2012.05.014

7. European Union (1993) Council Regulation (EEC), No 793/93 of 23 March1993 on the evaluation and control of the risks of existing substances (OJ L84, 5 April 1993). European Union, Brussels.

8. Feng L, Liu H, Cheng DD, Mao XM, Wang Y, Wu Z, Wu Q (2018) Characterization and Genome Analysis of a Phthalate Esters-Degrading Strain Sphingobium yanoikuyae SHJ. BioMed Research International Article ID 3917054: 8. https://doi.org/10.1155/2018/3917054

9. Feng NX, Yu J, Mo CH, Zhao HM, Li YW, Wu BX, Wong MH et al. (2018) Biodegradation of di-n-butyl phthalate (DBP) by a novel endophytic Bacillus megaterium strain YJB3. Science of the Total Environment: 616-617, 117-127. https://doi.org/10.1016/j.scitotenv.2017.10.298

10. Gao DW, Wen ZD (2016) Phthalate esters in the environment: a critical review of their occurrence, biodegradation, and removal during wastewater treatment processes. Science of the total Environment 541: 986-1001. https://doi.org/10.1016/j.scitotenv.2015.09.148

11. Han R (2008) Phthalate biodegradation: gene organization, regulation and detection. ProQuest. https://doi.org/doi:10.7282/T3154HD7

12. He Z, Xiao H, Tang L, Min H, Lu Z (2013) Biodegradation of di- $n$-butyl phthalate by a stable bacterial consortium, HD-1, enriched from activated sludge. Bioresource Technology 128: 526-532. https://doi.org/10.1016/j.biortech.2012.10.107

Page $7 / 14$ 
13. Heo J, Cho HY, Kim MA, Hamada M, Tamura T, Saitou S, Kim SJ and Kwon SW (2020) Microbacterium protaetiae sp. nov., isolated from gut of larva of Protaetia brevitarsis seulensis. International Journal of Systematic Evolutionary Microbiology 70: 2226-2232. https://doi.org/10.1099/ijsem.0.003967

14. Huang YH, Huang XJ, Chen XH, Cai QY, Chen SH, Mo CH, Lü HX, Wong MH (2018) Biodegradation of di-butyl phthalate (DBP) by a novel endophytic bacterium Bacillus subtilis and its bioaugmentation for removing DBP from vegetation slurry. Journal of Environmental Management 224: 1-

9. https://doi.org/10.1016/j.jenvman.2018.07.023

15. Iwata M, Imaoka T, Nishiyama T, Fujii T (2016) Re-characterization of mono-2-ethylhexyl phthalate hydrolase belonging to the serine hydrolase family. Journal of Bioscience and Bioengineering122: 140-145. https://doi.org/10.1016/j.jbiosc.2016.01.008

16. Jin DC, Kong X, Liu HJ, Wang XX, Deng Y, Jia MH, Yu XY (2016) Characterization and Genomic Analysis of a Highly Efficient Dibutyl Phthalate-Degrading Bacterium Gordonia sp. Strain QH-12. International Journal of Molecular Science 17: 1012. https://doi.org/10.3390/ijms17071012

17. Kim M, Oh HS, Park SC, Chun J (2014) Towards a taxonomic coherence between average nucleotide identity and 16SrRNA gene sequence similarity for species demarcation of prokaryotes. International Journal of Systematic and Evolutionary Microbiology 64(2): 346-

351. https://doi.org/10.1099/ijs.0.059774-0

18. Latini G, Del Vecchio A, Massaro M, Verrotti A, De Felice C (2006) Phthalate exposure and male infertility. Toxicology 226 (2-3): 90 98. https://doi.org/10.1016/j.tox.2006.07.011

19. Lei J, Wei S, Ren L, Hu S and Chen P (2017) Hydrolysis mechanism of carbendazim hydrolase from the strain Microbacterium sp. djl-6F. Journal of Environmental Sciences 54: 171-177. https://doi.org/10.1016/j.jes.2016.05.027

20. Li J, Chen JA, Zhao Q, Li X and Shu W (2006) Bioremediation of environmental endocrine disruptor di- $n$-butyl phthalate ester by Rhodococcus ruber. Chemosphere 65(9): 1627-1633. https://doi.org/10.1016/j.chemosphere.2006.03.005

21. Liang DW, Zhang T, Fang HHP, He JZ (2008) Phthalates biodegradation in the environment. Applied Microbiology and Biotechnology 80:183198. https://doi.org/10.1007/s00253-008-1548-5

22. Liu DD, Yan JL, Wang L, Zhang YZ, Liu DL, Geng H, Xiong L (2016) Characterization of the phthalate acid catabolic gene cluster in phthalate acid esters transforming bacterium-Gordonia sp. strain HS-NH1. International Biodeterioration \& Biodegradation, 106: 3440. https://doi.org/10.1016/j.ibiod.2015.09.019

23. Lü H, Mo CH, Zhao HM, Xiang L, Katsoyiannis A, Li YW, Cai QY, Wong MH (2018) Soil contamination and sources of phthalates and its health risk in China: a review. Environment Research 164: 417-429. https://doi.org/10.1016/j.envres.2018.03.013

24. Lu MY, Jiang WK, Gao QQ, Zhang ML, Hong Q (2020) Degradation of dibutyl phthalate (DBP) by a bacterial consortium and characterization of two novel esterases capable of hydrolyzing PAEs sequentially. Ecotoxicology and Environmental Safety 195:

110517. https://doi.org/10.1016/j.ecoenv.2020.110517

25. Mathieu-Denoncourt J, de Solla SR, Langlois VS (2015) Chronic exposures to monomethyl phthalate in western clawed frogs. General and Comparative Endocrinology 219: 53-63. https://doi.org/10.1016/j.ygcen.2015.01.019

26. Nahurira R, Ren L, Song J, Jia Y, Wang J, Fan S, Wang H, Yan Y (2017) Degradation of di-(2-ethylhexyl) phthalate by a novel Gordonia alkanivorans strain YC-RL2. Current Microbiology 74: 1-11. https://doi.org/10.1007/s00284-016-1159-9

27. Philip JM, Aravind UK, Aravindakumar CT (2018) Emerging contaminants in Indian environmental matrices-A review. Chemosphere 190: $307-$ 326. https://doi.org/10.1016/j.chemosphere.2017.09.120

28. Qin W, Zhu Y, Fan F, Wang Y, Liu X, Ding A, Dou J (2017) Biodegradation of benzo (a) pyrene by Microbacterium sp. strain under denitrification: Degradation pathway and effects of limiting electron acceptors or carbon source. Biochemical Engineering Journal 121: 131138. https://doi.org/10.1016/j.bej.2017.02.001

29. Ren L, Lin Z, Liu HM, Hu HQ (2018) Bacteria-mediated phthalic acid esters degradation and related molecular mechanisms. Applied Microbiology and Biotechnology 102: 1085-1096. https://doi.org/10.1007/s00253-017-8687-5

30. Ricken B, Fellmann O, Kohler HPE, Schaffer A, Corvini PFX, and Kolvenbach BA (2015) Degradation of sulfonamide antibiotics by Microbacterium sp. strain BR1- elucidating the downstream pathway. New Biotechnology 32 (6): 710-715. https://doi.org/10.1016/j.nbt.2015.03.005

31. Schippers A (2005) Microbacterium oleivorans sp. nov. and Microbacterium hydrocarbonoxydans sp. nov., novel crude-oil-degrading Gram-positive bacteria. International Journal of Systematic and Evolutionary Microbiology 55(2): 655-660. https://doi.org/10.1099/ijs.0.63305-0

32. Suzuki K, Hamada M, Genus I, Orla-Jensen M. 179AL emend. Takeuchi and Hatano 1998b, 744VP. In: Goodfellow M, Kämpfer P, Busse HJ, Trujillo ME and Suzuki K (editors). Bergey's Manual of Systematic Bacteriology. 2012. Athens, 1919: 814-852. https://link.springer.com/book/10.1007\%2F978-0-38768489-5

33. Shen S, Wang XY, Wang HX, Ren H, Lü ZM (2019) Advances in biodegradation of phthalates esters. Chinese Journal of Biotechnology 35 (11): 21042120. https://doi.org/10.13345/j.cjb.190177

34. Stojanoska MM, Milosevic N, Milic N, Abenavoli L (2017) The influence of phthalates and bisphenol A on the obesity development and glucose metabolism disorders. Endocrine 55 (3): 666-681. https://doi.org/10.1007/s12020-016-1158-4

35. Tichonovas M, Krugly E, Jankunaite D, Racys V, Martuzevicius D (2017) Ozone-UV-catalysis based advanced oxidation process for wastewater treatment. Environmental Science and Pollution Research 24: 17584-17597. https://doi.org/10.1007/s11356-017-9381-y

36. US EPA, 1992 and update. Code of federal regulations. 40 CFR, Part 136 Union E. 1993. Council Regulation (EEC), No $793 / 93$ of 23 March 1993 on the evaluation and control of the risks of existing substances (OJ L84, 5 April 1993). European Union, Brussels.

37. Wang YY, Fan YZ, Gu JD (2003) Aerobic degradation of phthalic acid by Comamonas acidovoran Fy-1 and dimethyl phthalate ester by two reconstituted consortia from sewage sludge at high concentrations. World Journal of Microbiology and Biotechnology 19:811-

Page $8 / 14$ 
815. https://doi.org/10.1023/A:1026021424385

38. Wang YY, Li FF, Ruan XL, Song J, Lv, L, Chai LY, Yang ZH, Luo L (2017) Biodegradation of di-n-butyl phthalate by bacterial consortium LV-1 enriched from river sludge. PLoS ONE 12(5): e0178213. https://doi.org/10.1371/journal.pone.0178213

39. Wu XL, Wang YY, Dai QY, Liang RX, Jin DC (2011) Isolation and characterization of four di-n-butyl phthalate (DBP)-degrading Gordonia sp. strains and cloning the 3, 4-phthalate dioxygenase gene. World Journal of Microbiology Biotechnology 27: 2611-2617. https://doi.org/10.1007/s11274-011-0734-2

40. Wu J, Liao X, Yu F, Wei Z, Yang L (2013) Cloning of a dibutyl phthalate hydrolase gene from Acinetobactersp. strain M673 and functional analysis of its expression product in Escherichia coli. Applied Microbiology and Biotechnology 97: 2275-2275 https://doi.org/10.1007/s00253-012-4232-8

41. Xu X, Li H, Gu J (2005) Biodegradation of an endocrine-disrupting chemical dibutyl phthalate ester by Pseudomonas fluorescens B-1. International Biodeterioration \& Biodegradation 55 (1): 9-15. https://doi.org/10.1016/j.procbio.2011.01.031

42. Yang J, Guo CL, Liu SS, Liu WT, Wang H, Dang Z, Lu G (2018) Characterization of a di- $n$-butyl phthalate-degrading bacterial consortium and its application in contaminated soil. Environmental Science and Pollution Research 25(18): 17645-17653. https://doi.org/10.1007/s11356-018-1862-0

43. You S, Hu Y, Liu X, Wei C, Wei C (2018) Synergetic removal of $\mathrm{Pb}$ (II) and dibutyl phthalate mixed pollutants on $\mathrm{Bi}_{2} \mathrm{O}_{3}-\mathrm{TiO}_{2}$ composite photocatalyst under visible light. Applied Catalysis B - Environmental 232: 288-298. https://doi.org/10.1016/j.apcatb.2018.03.025

44. Yu Y, Yin H, Peng H, Lu G and Dang Z (2019) Proteomic mechanism of decabromodiphenyl ether (BDE-209) biodegradation by Microbacterium Y2 and its potential in remediation of BDE-209 contaminated water-sediment system. Journal of Hazardous Materials:

121708. https://doi.org/10.1016/j.jhazmat.2019.121708

45. Zhao HM, Du H, Feng NX, Xiang L, Li YW, Li H, Cai QY, Mo CH (2016) Biodegradation of di- $n$-butyl phthalate and phthalic acid by a novel Providencia sp. 2D and its stimulation in a compost-amended soil. Biology and fertility of soils: Cooperating Journal of the International Society of Soil Science 52 (1): 65-76. https://doi.org/10.1007/s00374-015-1054-8

\section{Figures}

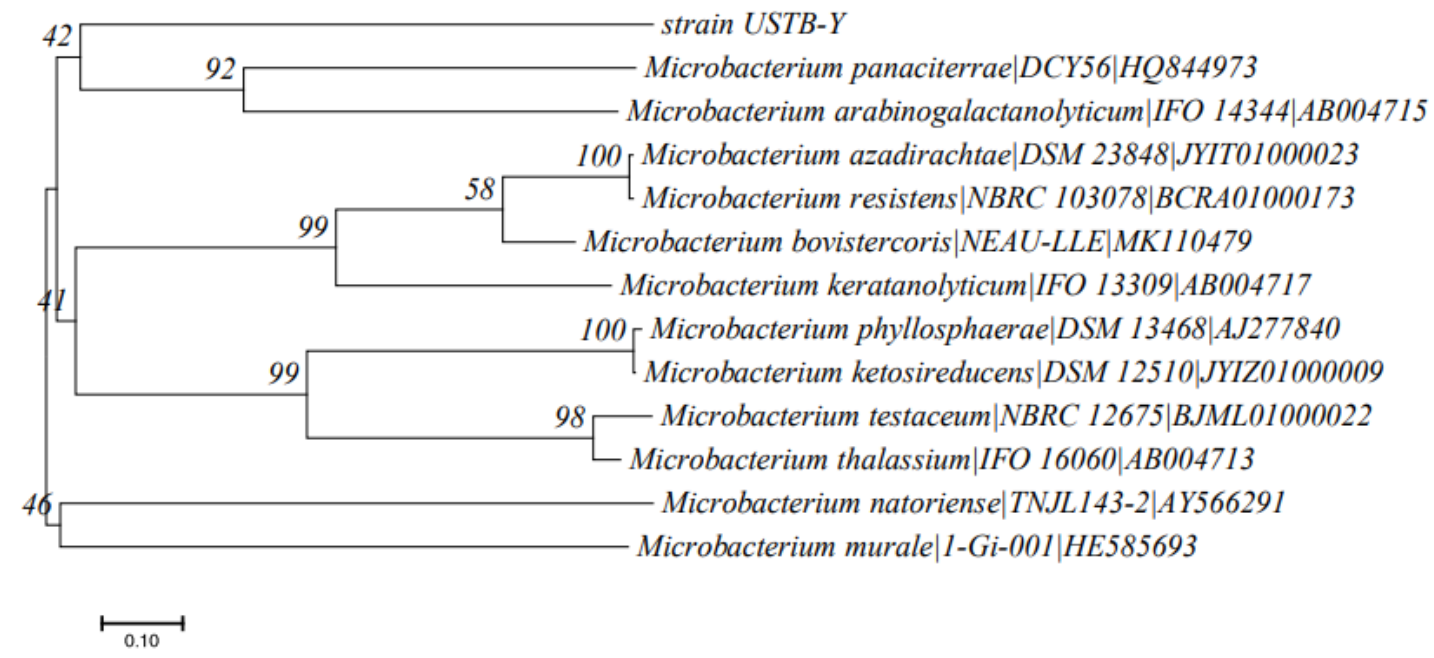

Figure 1

Phylogentic tree of strain USTB-Y based on 16S rDNA sequences by the neighbor-joining approach 


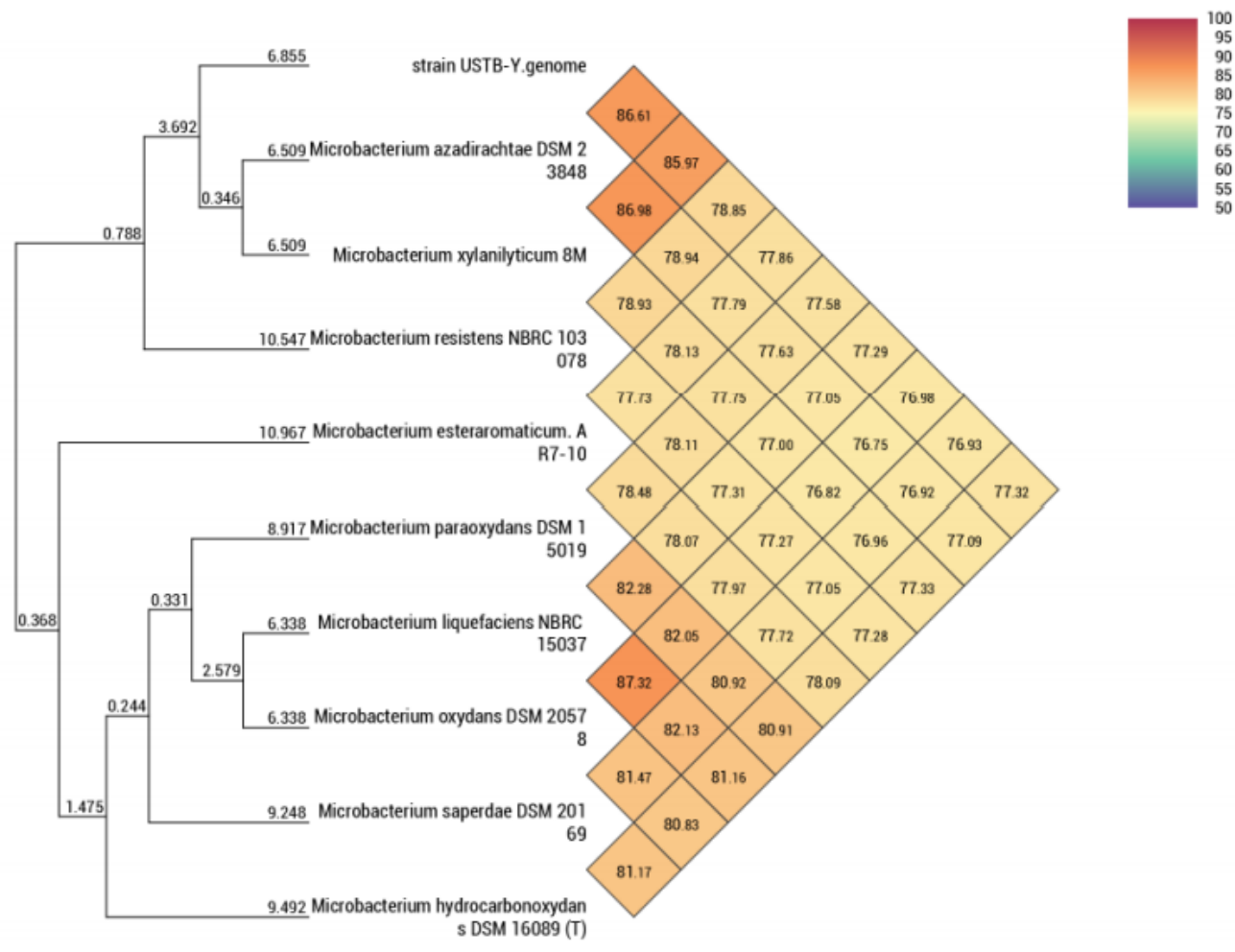

\section{Figure 2}

Phylogenetic analyses of ten genomes of Microbacterium sp. USTB-Y and representative related Microbacterium species by OAT. M. azadirachtae DSM23848 (GCA_000956545.1), M. xylanilyticum 8M (GCA_902506375.1), M. resistens NBRC103078 (GCA_001552355.1), M. esteraromaticum AR7-10 (GCA_001878835.1)『M. paraoxydans DSM15019 (GCA_900105335.1)『M. liquefaciens NBRC15037 (GCA_006539765.1), M. oxydans DSM20578 (GCA_008868025.1), M. saperdae DSM20169 (GCA_006716345.1), M. hydrocarbonoxydans DSM16089 (GCA_900105205.1) were downloaded from NCBI for phylogenetic analysis.

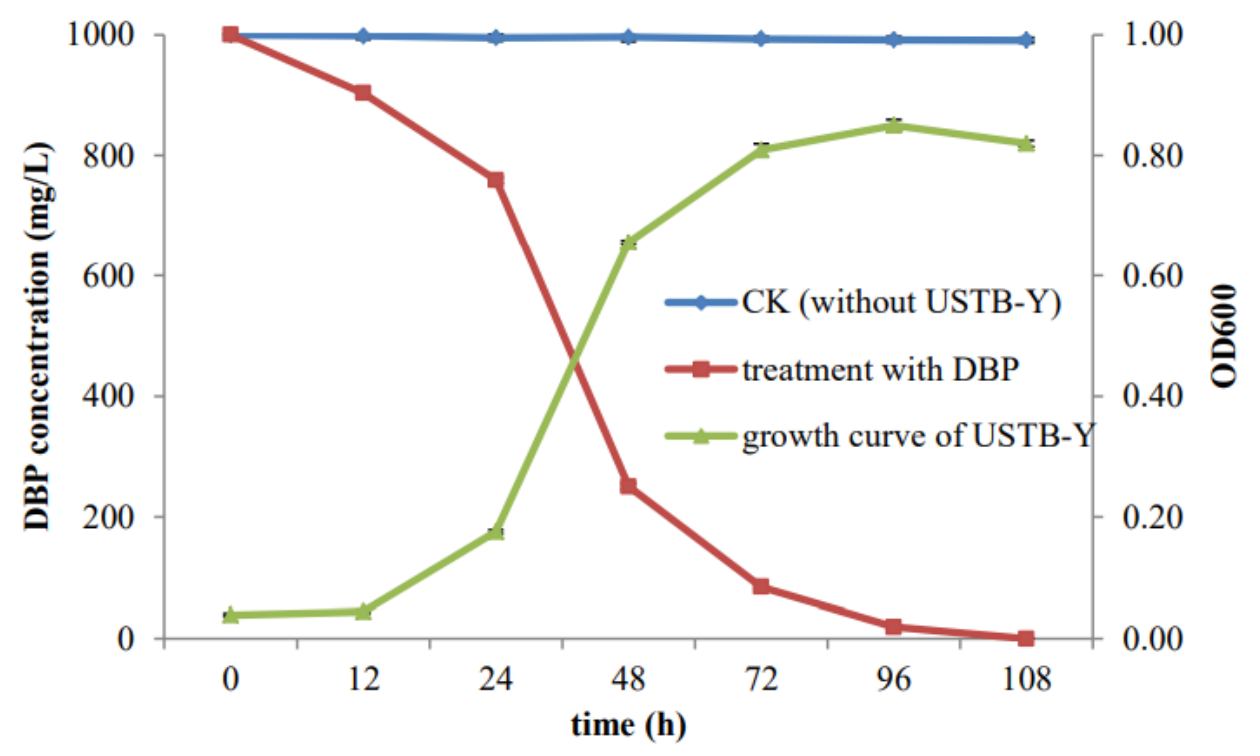

Figure 3

Growth curve of strain USTB-Y and biodegradation dynamic of DBP in MSM media. CK: control group, without USTB-Y. 


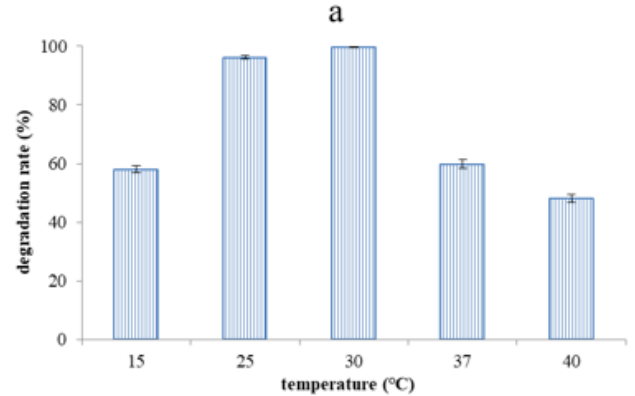

b
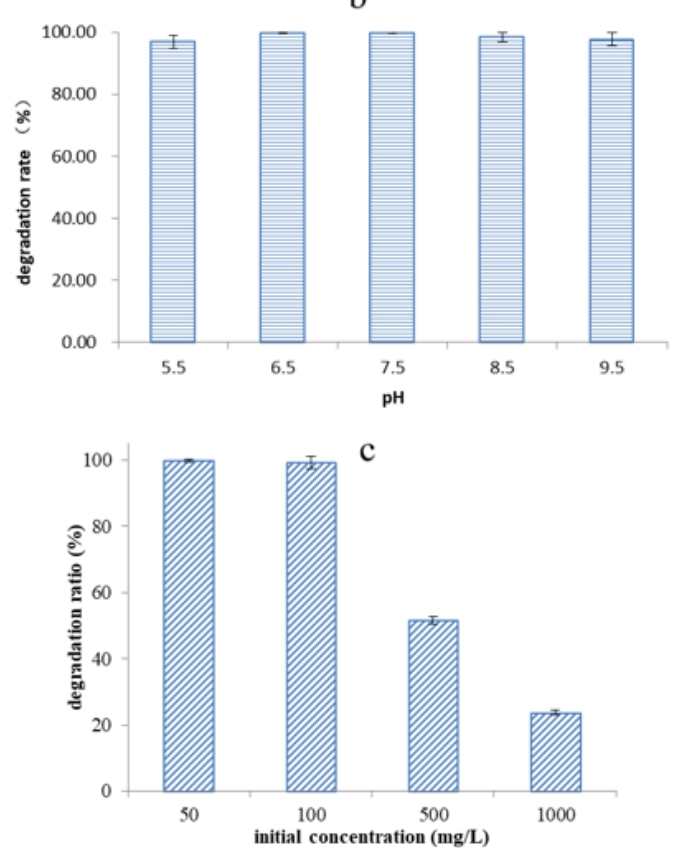

Figure 4

Effects of temperature (a), $\mathrm{pH}$ (b), and initial concentrations (c) on DBP degradation rate by USTB-Y cultured for $24 \mathrm{~h}$. 
a

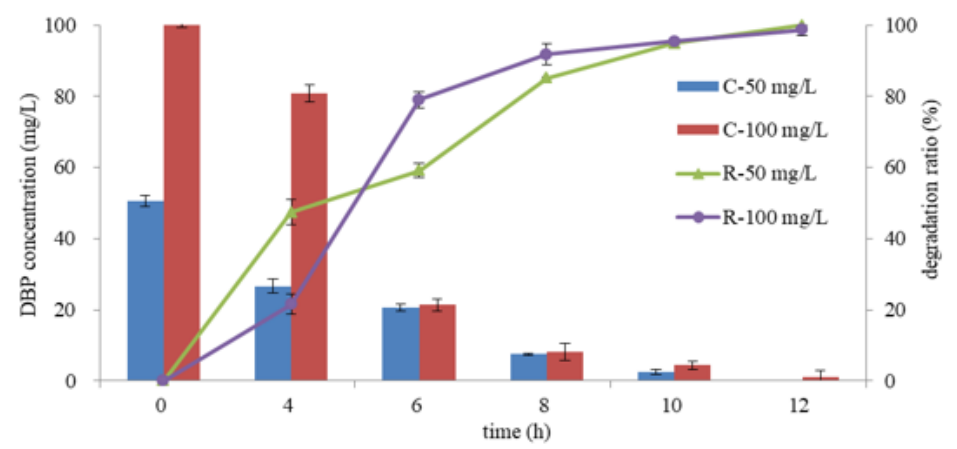

b

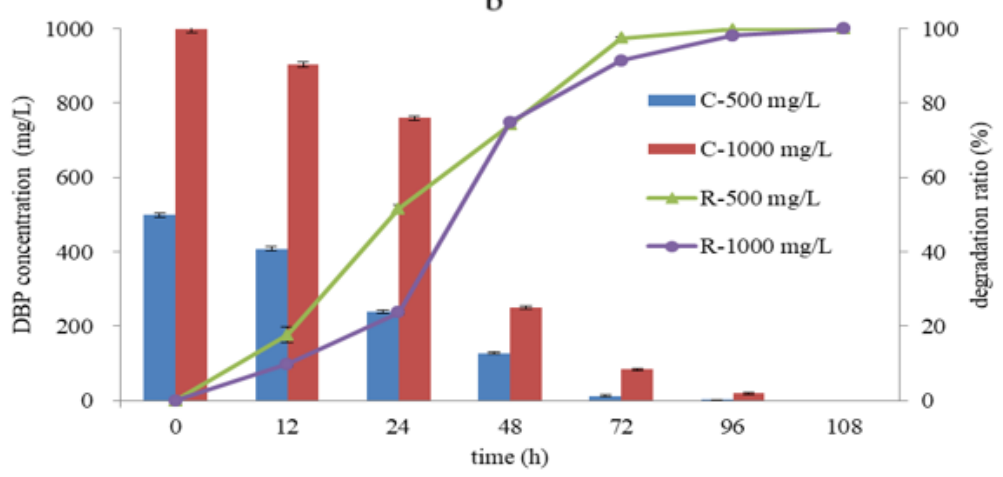

\section{Figure 5}

The residual concentrations (C) and biodegradation rate (R) of DBP by strain USTB-Y in MSM. a Initial concentrations of 50 and 100 mg/L; $b$ Initial concentrations of 500 and $1000 \mathrm{mg} / \mathrm{L}$.

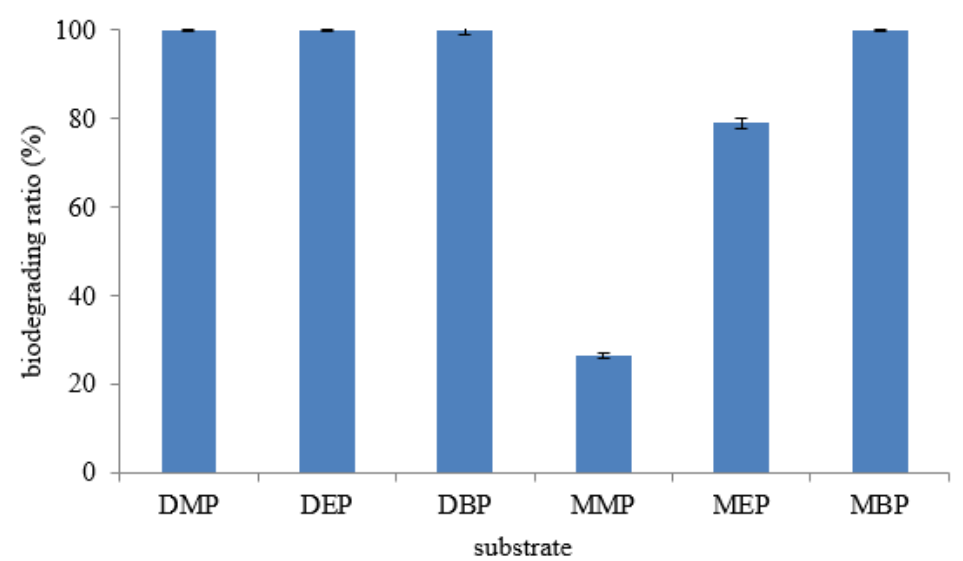

\section{Figure 6}

Degradation of individual PAEs by train USTB-Y. 

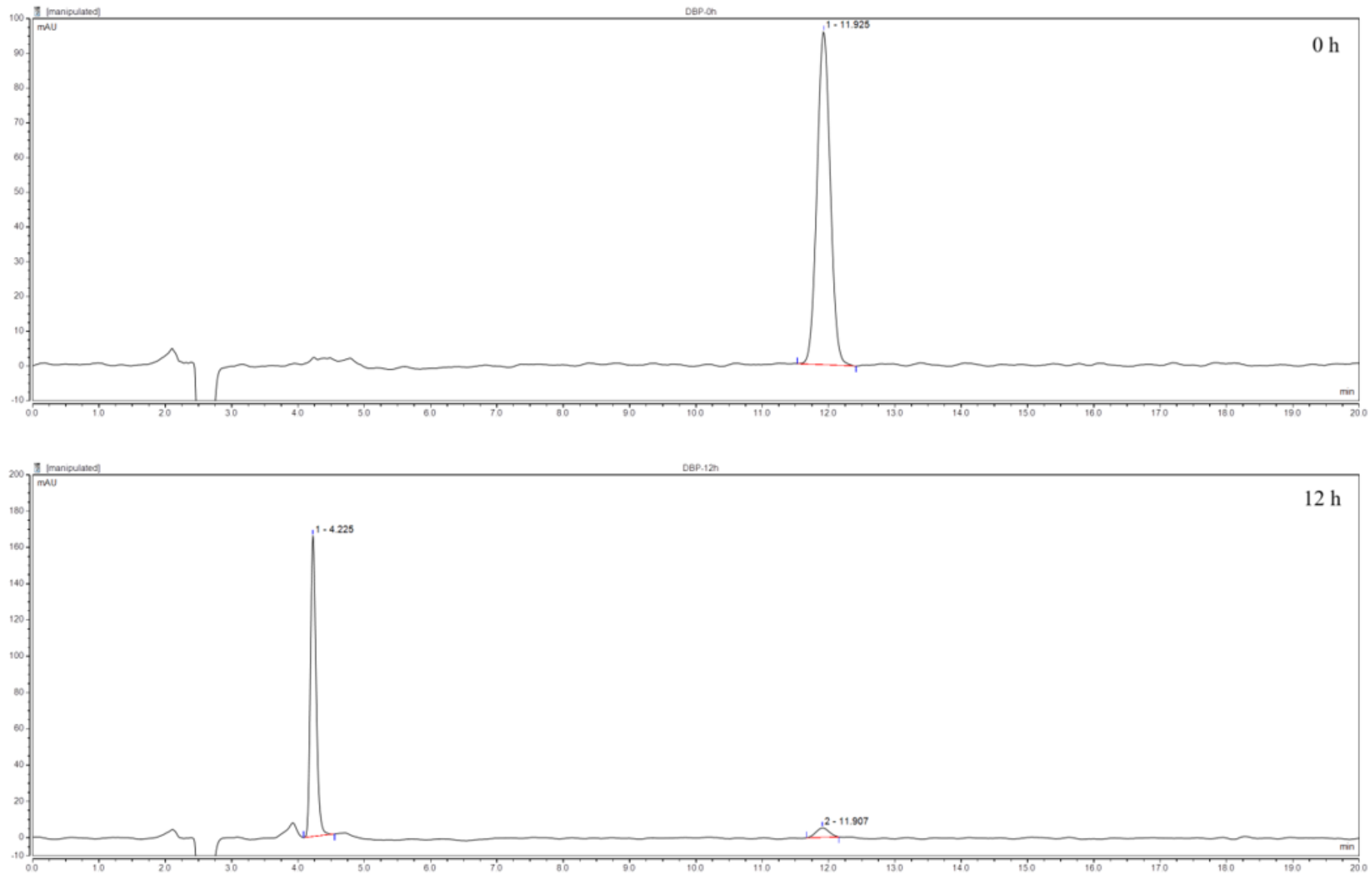

Figure 7

HPLC chromatograms for DBP biodegradation by USTB-Y in MSM after the following times: a $0 \mathrm{~h}$; $\mathrm{b} 4 \mathrm{~h}$; c $10 \mathrm{~h}$; $\mathrm{d} 12 \mathrm{~h}$.
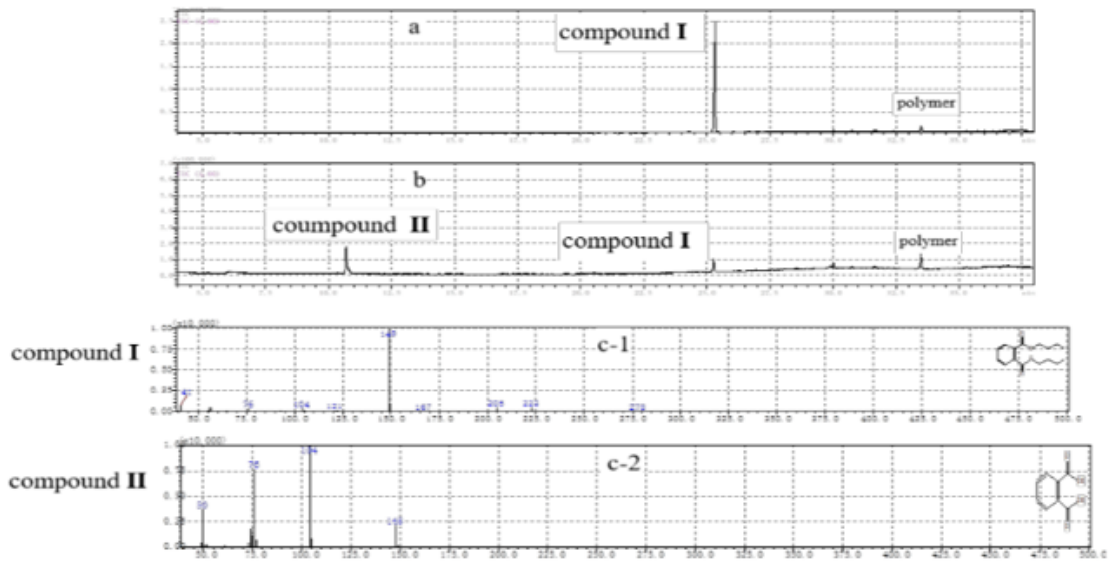

d

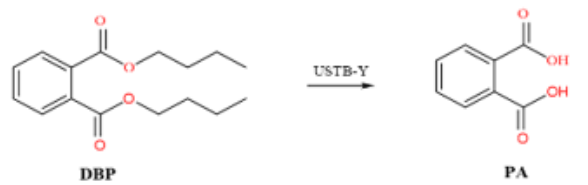

Figure 8

GC-MS analysis of DBP biodegradation product and the proposed pathway by strain USTB-Y. (a) total ion chromatogram of $0 \mathrm{~h}$ sample; (b) total ion

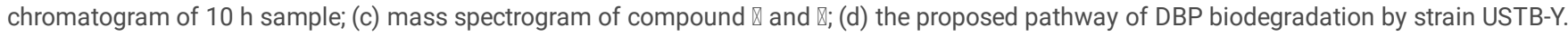




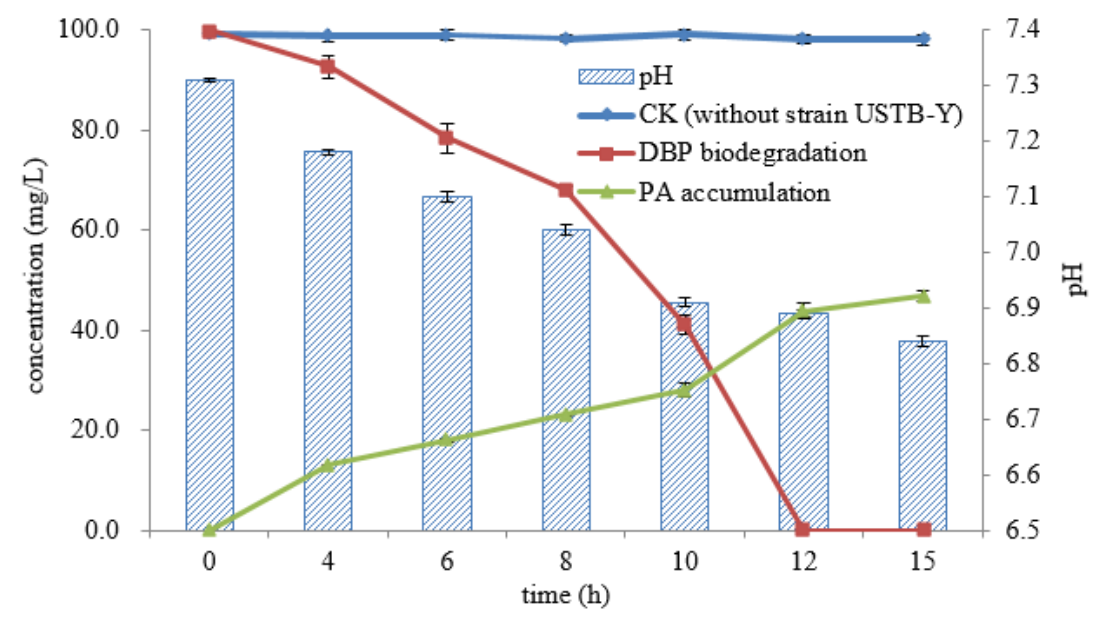

Figure 9

PA accumulation during DBP degradation by Microbacterium sp. USTB-Y.

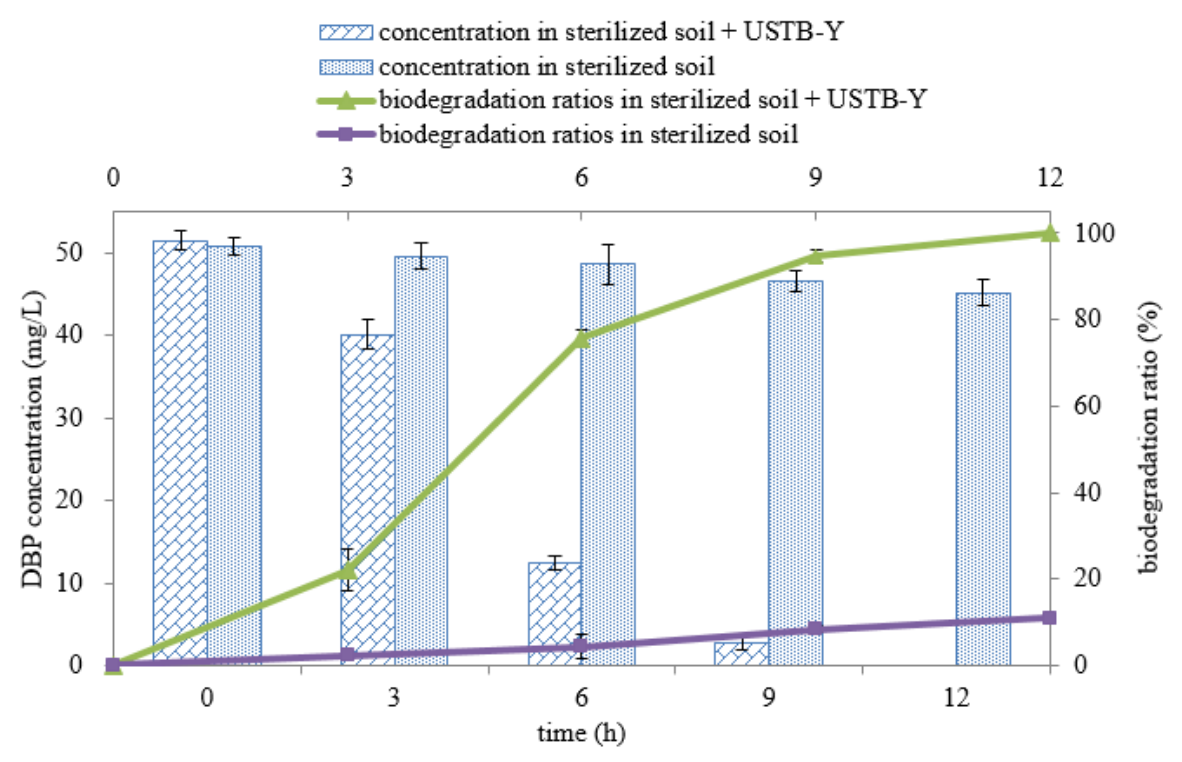

\section{Figure 10}

The residual concentration and degradation rate of DBP in artificially contaminated soil. Error bars indicate the standard error of three replicates.

\section{Supplementary Files}

This is a list of supplementary files associated with this preprint. Click to download.

- OnlineResource1picturesofUSTBY.pdf

- OnlineResource2KEGGpathway.xlsx

- OnlineResource3KEGGannotation.xIsx

- OnlineResource4genesforesteraseandhydrolase.xlsx

- OnlineResource5aromaticcompoundsdegradationpatway.pdf 